\title{
Transfusion Reactions in Pediatric Cancer Patients
}

\author{
Cakra Jati Pranata, ${ }^{1}$ Nur Suryawan, ${ }^{2}$ Delita Prihatni ${ }^{3}$ \\ ${ }^{1}$ Faculty of Medicine Universitas Padjadjaran, Indonesia, ${ }^{2}$ Department of Child Health \\ Faculty of Medicine Universitas Padjadjaran/Dr. Hasan Sadikin General Hospital Bandung, \\ Indonesia, ${ }^{3}$ Department of Clinical Pathology Faculty of Medicine Universitas Padjadjaran/ \\ Dr. Hasan Sadikin General Hospital Bandung, Indonesia
}

\section{Abstract}

Background: Transfusion is an essential component of supportive management for cancer patients with anemia and thrombocytopenia. It is generally safe; however, it has several risks and complications including those caused by transfusion reactions. This study aimed to describe transfusion reactions in pediatric cancer patients in a tertiary hospital in Indonesia.

Methods: This was a descriptive cross-sectional study with a total sampling method. A prospective analysis was performed on episodes of blood transfusion in pediatric patients aged younger than 18 years old with cancer and were hospitalized at the Department of Child Health of the hospital from July to August 2019. After the consent of the parents, the patients were interviewed for various transfusion reactions. Data collected were presented using tables and charts.

Results: Leukemia was the most frequent cancer in children cancer patients who need transfusion. Out of 42 children included, 155 episodes of transfusion were observed with 22 episodes showed transfusion reactions (14.2\%). The most frequent manifestations were pruritus (31.8\%), followed by combination of pruritus and erythema $(27.4 \%)$ and fever (13.6\%). These reactions appeared mostly in 1 to 2 hours $(27.2 \%)$, with most were mild reactions $(59.1 \%)$.

Conclusions: Transfusion reactions mostly occur among pediatric patients with cancer in the acute phase with clinical manifestation of allergic reactions, predominantly mild. Early identification of these reactions will result in better treatment and prevention for recurrence of transfusion reactions.

Keywords: Allergy, cancer, children, leukemia

\section{Introduction}

Suppression of bone marrow is frequently occurred in patients with cancer due to its disease as well as an effect of chemotherapy, resulting in a decrease of red cells, leucocytes, and platelets. The primary management of low red cells and platelet counts or anemia and thrombocytopenia, respectively, is blood transfusion which is an essential component of supportive management. ${ }^{1}$ Generally, transfusion tends to be safe and has many benefits, however, there is still a risk and complication known as transfusion reactions. ${ }^{1}$ These reactions vary from mild to life-threatening. Reactions can occur during transfusion (acute reactions) or in days, even weeks, after the transfusion (delayed reactions). ${ }^{2}$ Several factors that affect transfusion reactions, among others the patient comorbidity. ${ }^{3}$ Due to a decrease of immunity, patient with cancer tends to suffer from transfusion reactions. ${ }^{4}$ Moreover, discrepancy on blood cell antigen ${ }^{5}$ is also related to a higher risk of reaction from a blood transfusion. ${ }^{3}$

The recommendation of blood transfusion to patients with cancer is a modification component of packed red cells or thrombocyte concentrate of which the leukocyte component has been reduced and irradiated. ${ }^{6}$ However, some places still use conventional packed red cells and thrombocyte concentrate that might increase the risk of transfusion reactions. ${ }^{6}$ 
Data on transfusion reactions among pediatric cancer patients at Dr. Hasan Sadikin General Hospital Bandung as a referral hospital in West Java is still limited. Therefore, the study on transfusion reactions among pediatric patients with cancer was explored.

\section{Methods}

This study design was a cross-sectional study with a descriptive approach. The technique of data collection was the total sampling method. A prospective analysis was performed on all pediatric patients aged younger than 18 years old that were diagnosed with cancer and hospitalized at Dr. Hasan Sadikin Bandung General Hospital from July to August 2019.

Data about reaction transfusion was collected by using a standardized closed question interview method based on the form of transfusion reaction report from the Department of Clinical Pathology Dr. Hasan Sadikin Bandung General Hospital. Data were analyzed according to their transfusion episode established, based on the transfusion time and blood component. The exclusion criteria were the patient who did not fill in the questionnaire. The data was taken daily, for
Table 1 Clinical Characteristic of Pediatrics Patients with Cancer Undergone Blood Transfusion in Dr. Hasan Sadikin General Hospital Bandung Period July-August 2019

\begin{tabular}{lcc}
\hline & Total (N=43) & \\
\cline { 2 - 3 } & N & $\%$ \\
\hline Age group & 10 & \\
$0-<5$ years old & 13 & 23.8 \\
5-<10 years old & 19 & 31.0 \\
10-18 years old & & 45.2 \\
Gender & 19 & \\
Male & 23 & 54.8 \\
Female & & 45.2 \\
Blood type & 15 & \\
A & 8 & 35.7 \\
B & 6 & 19.0 \\
AB & 13 & 14.3 \\
O & 41 & 31.0 \\
Rhesus + & 1 & 97.6 \\
Rhesus - & & 2.4 \\
Clinical Diagnosis & 1 & \\
Acute Leukemia & 7 & 2.4 \\
Acute Myeloblastic Leukemia & 1 & 16.7 \\
Acute Lymphoblastic Leukemia & 1 & 52.4 \\
Chronic Myeloblastic Leukemia & 22 & 2.4 \\
Neuroblastoma & 2 & 4.8 \\
Retinoblastoma & 5 & 4.8 \\
Osteosarcoma & 1 & 2.4 \\
Non Hodgkin's Cancer Lymphoma & & 2.4 \\
Hodgkin' Cancer Lymphoma & & \\
\hline
\end{tabular}


Table 2 Clinical Manifestation of Transfusion Reactions Based on Blood Components

\begin{tabular}{|c|c|c|c|c|c|c|}
\hline \multirow{3}{*}{ Clinical Manifestation } & \multicolumn{4}{|c|}{ Blood components } & \multirow{2}{*}{\multicolumn{2}{|c|}{ Total }} \\
\hline & \multicolumn{2}{|c|}{ Packed Red Cells } & \multicolumn{2}{|c|}{$\begin{array}{c}\text { Thrombocyte } \\
\text { Concentrate }\end{array}$} & & \\
\hline & $\mathbf{N}$ & $\%$ & $\mathbf{N}$ & $\%$ & $\mathbf{N}$ & $\%$ \\
\hline Fever, pruritus, and erythema & 1 & 4.5 & 1 & 4.5 & 2 & 9.1 \\
\hline Pruritus and erythema & 4 & 18.3 & 2 & 9.1 & 6 & 27.4 \\
\hline Fever and shortness of breath & 1 & 4.5 & - & - & 1 & 4.5 \\
\hline Pruritus & 3 & 13.5 & 4 & 18.3 & 7 & 31.8 \\
\hline Shortness of breath & 1 & 4.5 & - & - & 1 & 4.5 \\
\hline Fever & 2 & 9.1 & 1 & 4.5 & 3 & 13.6 \\
\hline Shivering & - & - & 1 & 4.5 & 1 & 4.5 \\
\hline Back Pain & - & - & 1 & 4.5 & 1 & 4.5 \\
\hline
\end{tabular}

30 consecutive days at a time. After informed consent to the parents, the interview was conducted with both parents and patients. The patient aged older than 12 years old was interviewed using the auto anamnesis method, and for patients aged younger than 12 years old using alloanamnesis method. The data that was gathered then reviewed in the form of blood transfusion monitoring data that was recorded in the medical record of the patient. This study was approved by The Research Ethics Committee of Universitas Padjajaran no. 120/UL6.KP/ET/2019 and permission was given by The Medical Research Ethics Committee of Dr. Hasan Sadikin General Hospital Bandung no. LB/X.3/102/2018.

Variables of this study were patient identity (age, sex, blood type, and clinical diagnosis), transfusion episode (blood components), and transfusion reactions (clinical manifestation and onset). The data were analyzed using descriptive statistics and processed by using Microsoft $\circledast$ Excel 2016 and IBM $®$ SPSS $®$ version 22 . The data was then presented in the form of a table, percentage, and chart to draw patient identity, transfusion episodes, and transfusion reactions.

\section{Results}

In total, data on 42 patients with one hundred fifty-five episodes of transfusion were collected. Blood transfusion was mostly given to males (54.8\%). About half of the patients $(45.2 \%)$ were in the age group 10 to 18 years old. The most blood type in this study was blood type A (35.7\%) and rhesus $(+)(97.6 \%)$. The clinical diagnosis was acute

Table 3 Clinical Manifestation of Transfusion Reactions by the Diagnosis

\begin{tabular}{|c|c|c|c|c|c|c|}
\hline \multirow{3}{*}{ Clinical Manifestation } & \multicolumn{4}{|c|}{ Diagnosis } & \multirow{2}{*}{\multicolumn{2}{|c|}{ Total }} \\
\hline & \multicolumn{2}{|c|}{ Leukemia } & \multicolumn{2}{|c|}{ Non-Leukemia } & & \\
\hline & $\mathbf{N}$ & $\%$ & $\mathbf{N}$ & $\%$ & $\mathbf{N}$ & $\%$ \\
\hline Fever, pruritus, and erythema & 2 & 9.1 & 0 & 0 & 2 & 9.1 \\
\hline Pruritus and erythema & 4 & 18.3 & 2 & 9.1 & 6 & 27.4 \\
\hline Fever and shortness of breath & 1 & 4.5 & - & - & 1 & 4.5 \\
\hline Pruritus & 5 & 22.7 & 2 & 9.1 & 7 & 31.8 \\
\hline Shortness of breath & 1 & 4.5 & - & - & 1 & 4.5 \\
\hline Fever & 3 & 13.6 & - & - & 3 & 13.6 \\
\hline Shivering & 1 & 4.5 & - & - & 1 & 4.5 \\
\hline Back Pain & - & - & 1 & 4.5 & 1 & 4.5 \\
\hline
\end{tabular}


Table 4 Distribution of Transfusion Reactions Based on Onset

\begin{tabular}{lcc}
\hline & \multicolumn{2}{c}{ Transfusion Reactions } \\
\cline { 2 - 3 } & $\mathbf{N}$ & $\mathbf{\%}$ \\
\hline Onset & 1 & 4.5 \\
0-15 minutes & 4 & 18.3 \\
$>15-30$ minutes & 3 & 13.7 \\
$>$ 30 minutes-1 hour & 6 & 27.2 \\
$>1-2$ hours & 3 & 13.7 \\
$>$ 2-3 hours & 5 & 22.6 \\
$>3$ hr & & 59.1 \\
Type of acute transfusion reaction & 13 & 31.8 \\
Mild & 7 & 9.1 \\
Moderate-severe & 2 & \\
Life-threatening & & 2 \\
\hline
\end{tabular}

leukemia lymphoblastic (52.4\%), followed by acute myeloblastic leukemia (16.7\%). Of 155 transfusion episodes, 22 episodes had transfusion reactions (14.2\%) experienced by thirteen patients of whom two patients had repeated reactions.

Thrombocyte concentrate was frequently used in transfusion (54.2\%), followed by packed red cells $(45.8 \%)$. The clinical manifestations due to transfusion reactions were pruritus $(31.8 \%)$, followed by both pruritus and erythema (27.4\%) and fever $(13.6 \%)$. While investigating the reactions based on blood components, packed red cell was the component that was more related to transfusion reactions $(54.4 \%)$ as shown in table 2. Furthermore, leukemia was the most manifestation related to transfusion reactions (Table 3).

Based on the onset, most of the transfusion reactions occurred within 1 to 2 hours after starting transfusion $(27.2 \%)$ as depicted in Table 4. In this acute transfusion reaction, $59.1 \%$ experienced a mild reaction.

\section{Discussions}

This study has reported that the age group of 10 to 18 years and male are predominantly given a blood transfusion, similar to the study from Brazil. ${ }^{7}$ Based on epidemiological studies, cancer occurring between the ages of 15 and 30 years is 2.7 times more common than cancer occurring during the first 15 years of life. ${ }^{8}$ Susceptibility to cancer is generally higher in males, although some cancers are more common in women. ${ }^{9}$ Lymphoblastic leukemia acute is a type of cancer that frequently needs a transfusion. ${ }^{7}$ Leukemia is one of the most prevalent cancers in Indonesia.

Of 155 transfusion episodes, transfusion reactions have been reported in 22 episodes (14.2\%). Leukemia requires transfusion intensively and this cancer is the most cancer related to repeated transfusion reactions. Repeated blood transfusions might be associated with the production of alloantibodies against one or more antigens, which complicate subsequent transfusions, including the increased risk of delayed transfusion reactions. ${ }^{10}$ Furthermore, repeated transfusion reactions are also associated with patient comorbidity. ${ }^{3}$

Interestingly, the number of transfusion reactions in our study is relatively higher compared with the study conducted in Brazil that reported transfusion reactions of $1.13 \%{ }^{11}$ Generally, a patient with cancer is immune suppressed, leading to an increase in transfusion reaction risks. ${ }^{4}$ One of the reasons is the inability of the immune system to reject antigen received during transfusion, due to immunodeficiency states of $\mathrm{B}$ and $\mathrm{T}$ lymphocytes. Patients with cancer may have an undetected immunoglobulins level that causes the presence of discrepancy in blood cell antigen. ${ }^{5}$ Moreover, aside from cancer itself, the use of blood components affects transfusion reactions as well. ${ }^{12}$

The study in blood bank hospital has established a protocol that patients with cancer should be given leuco-depleted blood 
components. ${ }^{7}$ In contrast, most of the blood components for blood transfusion given to patients in this study are thrombocyte concentrate and followed by packed red cells; no leuco-depleted blood component. Packed red cells and thrombocytes can contain leukocytes, higher than the leuco-depleted blood component. ${ }^{13}$ This affects the component containing human leukocyte antigen (HLA) and proinflammatory cytokines such as IL$1 \beta$, IL-6, IL-8, and TNF that are relatively high and can increase the incidents of transfusion reactions, especially non-hemolytic reactions. ${ }^{6}$ The use of leuco-depleted blood component is more effective to reduce the risk of transfusion reactions. ${ }^{12}$

Furthermore, our study has shown that most of the transfusion reactions have been recorded in the acute phase ( $>24$ hours) with most patients experienced mild reactions. Interestingly, transfusion reactions can occur in a shorter onset, which is within the first hour, ${ }^{14}$ or even in 15 minutes after starting transfusion. ${ }^{1}$ Taken together, the transfusion reactions are acute and not delayed. One possibility is an increased Th2 and decreased Th1 profile that is related to an increase risk of hypersensitivity. ${ }^{15}$ IgE recipients may react to the donor of plasma protein that tends to release mast cell mediators. ${ }^{16}$ This phenomenon also explains that the clinical manifestation of pruritus appeared the most. Similar to the study in Brazil, exposed allergic reactions is transfusion reactions that are generally occurring within pediatric patients with cancer. ${ }^{3}$ However, a fever could be the most frequent transfusion reaction as opposed in a study from Uganda. ${ }^{11}$ Interestingly, the number of pruritus incidents is high, suggesting as one of the allergic manifestations (31.8\%) shows in a relationship of patients' age on transfusion reactions. The children aged 1 to 2 years old tend to be more susceptible to nonhemolytic transfusion reactions, whereas those older than 2 years are prone to experience allergic reactions, nevertheless, it may be required further study. ${ }^{3}$

This study has limitations among others that the transfusion reactions result is not from observation but interview. The data might give a recall bias. A good clinical observation is the need for further study.

To conclude, transfusion reactions in children with cancer mostly occur in leukemia with frequent allergic reactions as clinical manifestation. The onset is acute with most experienced as a mild reaction. Since the occurrence of transfusion reactions in children with cancer is relatively higher than total transfusion reactions at Dr. Hasan Sadikin General Hospital, it requires an effort to decrease and prevent repeated transfusion reactions by utilizing the leukocyte-reduction technology and gamma irradiation. The form for transfusion reactions needs to be improved as monitoring and evaluation of the occurrence of transfusion reaction.

\section{References}

1. Chakravarty-vartak U, Shewale R, Vartak S, Faizal F, Majethia N. Adverse reactions of blood transfusion: a study in a tertiary care hospital. Int J Sci Stud 2016;4(2):90-4.

2. Payung W, Rachmawati AM, Arif M. Factors in acute transfusion reaction. Indonesian Journal of Clinical Pathology and Medical Laboratory. 2016;22(3):274-8.

3. Pedrosa AK, Pinto FJ, Lins LD, Deus GM. Blood transfusion reactions in children: associated factors. J Pediatr (Rio J). 2013;89(4):400-6.

4. Dasararaju R, Marques MB. Adverse effects of transfusion. Cancer Control. 2015;22(1):16-25.

5. Subramaniyan R, Gaspar BL. A closer look into blood group discrepancy arising due to an underlying malignancy. Rev Bras Hematol Hemoter. 2016;38(4):361-3.

6. Simancas-Racines D, Osorio D, MartiCarvajal AJ. Arevalo-Rodriguez I. Leukoreduction for the prevention of adverse reactions from allogeneic blood transfusion. Cochrane Database Syst Rev. 2015;(12):CD009745.

7. de Freitas JV, de Almeida PC, Guedes MVC. Transfusion reactions profile in oncology pediatrics patients. J Nurs UFPE on line. 2014;8(7):3030-8.

8. Bleyer A, Viny A, Barr R. Cancer in 15- to 29-years-olds by primary site. Oncologist. 2006;11(6):590-601

9. Dorak MT, Karpuzoglu E. Gender differences in cancer susceptibility: an inadequately addressed issue. Front Genet. 2012;3:268

10. Bhuva DK, Vachhani J. Red cell alloimmunization in repeatedly transfused patients. Asian J Transfus Sci. 2017;11(2):115-20.

11. Waiswa MK, Moses A, Seremba E, Ddungu H, Hume HA. Acute transfusion reactions at a national referral hospital in Uganda: a prospective study. Transfusion. 2014;54(11):2804-10.

12. Kato H, Uruma M, Okuyama Y, Fujita H, 
Handa M, Tomiyama Y, et al. Incidence of transfusion-related adverse reactions per patient reflects the potential risk of transfusion therapy in Japan. Am J Clin Pathol. 2013;140(2):219-24.

13. Nency YM, Sumanti D. Penggunaan transfusi komponen darah pada anak. Sari Pediatr. 2011;13(3):159-64.

14. Apriastini NKT, Ariawati K. Risk factors of acute blood transfusion reactions in pediatric patients in Sanglah General
Hospital. Bali Med J. 2017;6(3):534-8.

15. Yanagisawa R, Shimodaira S, Sakashita K, Hidaka Y, Kojima S, Nishijima F, et al. Factors related to allergic transfusion reactions and febrile non-haemolytic transfusion reactions in children. Vox Sang. 2016;110(4):376-84

16. Sharma S, Sharma P, Tyler LN. Transfusion of blood and blood products: Indications and complications. Am Fam Physician. 2011;83(6):719-24. 